\title{
Modeling Medical Oxygen Demand Using Box-Jenkins Methodology Applied Study on Soba University Hospital
}

\author{
Walid Sayed Mohamed Hamad $\operatorname{Karar}^{1}$, Ahmed Abdallah Hamdi ${ }^{2}$ \\ Sudan University of Science \& Technology
}

\begin{abstract}
This paper aim to find a suitable model to predict the demand of medical oxygen. The study data contained a number of 120 observations of oxygen consumption( in m3 ) were taken from Soba University Hospital in Khartoum state, since January 2005 to December 2014. We have used Box-Jenkins, Auto Regressive Integrated Moving Average (ARIMA) methodology for building forecasting model. Results suggest that ARIMA $(0,1,1)$ is the most suitable model to be used for predicting the demand of medical oxygen. For testing the forecasting accuracy Root Mean Square Error, Mean Absolute Error, and Mean Absolute Percentage Error are calculated.
\end{abstract}

Keywords: Modeling Medical Oxygen Demand, Box-Jenkins Methodology, ARIMA ,forecasting oxygen consumption

\section{Introduction}

The importance of medical oxygen as one of the most important medical needs necessary to remedial sections which is used in hospitals, especially in the treatment of acute medical patients in the short term in emergency departments such as respiratory diseases, acute pneumonia, asthma and pulmonary congestion due to heart failure or chronic conditions which are required in some cases. The research takes Box-Jenkins methodology to formulate the demand of the medical oxygen as a method commonly used in time-series models for forecasting analysis. Specifically since the time series is an important statistical topics dealing with the behavior of the phenomena analyzes and interprets over specific periods. The objectives of time series analysis can be summarized to obtain an accurate description of the special features of the process which is generate time series. And build a model to explain the behavior of the time series, and use the results to predict the behavior of the series in the future, in addition to control the process that generated the time series which examines what can happen when you change some of the parameters of the model. This study will contribute to provide accurate information for decision-makers which can helps them in the development of policies leading to the solution of the problem. And to know the real amount of medical oxygen for hospitals to avoid a shortage of the oxygen supply in the future.

Objectives:

\section{Methods}

This study aims to find the suitable ARIMA model which will use to predict the demand of medical oxygen for Soba University hospital as applied study.

\section{Data collection:}

The research data was taken from Soba University hospital which follow to Khartoum University represents one of biggest hospitals in Khartoum State, such as a availability of data are deal the researcher to choose the Soba University hospital as applied study of this research . The collected data contained (120) series of observations of monthly consumption of Oxygen, since January 2005 to December 2014.

\section{Box-Jenkins Methodology (Theoretical Background):}

\section{Statistical Methods}

In 1976 GEORGE E.P. BOX \& GWILYM.JENKINS are revised the edition of their book entitled "Time Series Analysis Forecasting and Control ". The book gave an explanation of the time series models stable and unstable including an auto-regressive integrated moving average (ARIMA) process, of order (p,d,q). The process is defined by:

$$
w_{t}=\emptyset_{1} w_{t-1}+\cdots+\emptyset_{p} w_{t-p}+a_{t}-\theta_{1} a_{t-1}-\cdots-\theta_{q} a_{t-q}
$$

The identification stage is the most important and also the most difficult: it consists to determine the adequate model from ARIMA family models. The most general Box-Jenkins model includes difference operators, autoregressive terms, moving average terms, seasonal difference operators, seasonal autoregressive terms, and seasonal moving average terms. This phase is founded on the study of autocorrelation and partial 
autocorrelation. The first step in developing a Box-Jenkins model is to determine if the series is stationary and if there is any significant seasonality that needs to be modeled.

\section{Testing for Non-Stationarity:}

1. Autocorrelation function (Box-Jenkins approach)-if autocorrelations start high and decline slowly, then series is non stationary, and should be differenced.

2. Dickey-Fuller test

$y t=a+b y t-1+$ ut would be a non stationary random walk if $b=1$. So to find out if $y$ has a "unit root" we regress: $\Delta y \mathrm{t}=\mathrm{a}+\mathrm{cyt}-1+\mathrm{ut}$ where $\mathrm{c}=\mathrm{b}-1$ and test hypothesis that $\mathrm{c}=0$ against $\mathrm{c}<0$ (like a "t-test").

\section{Iterative stages in the selection of the model :}

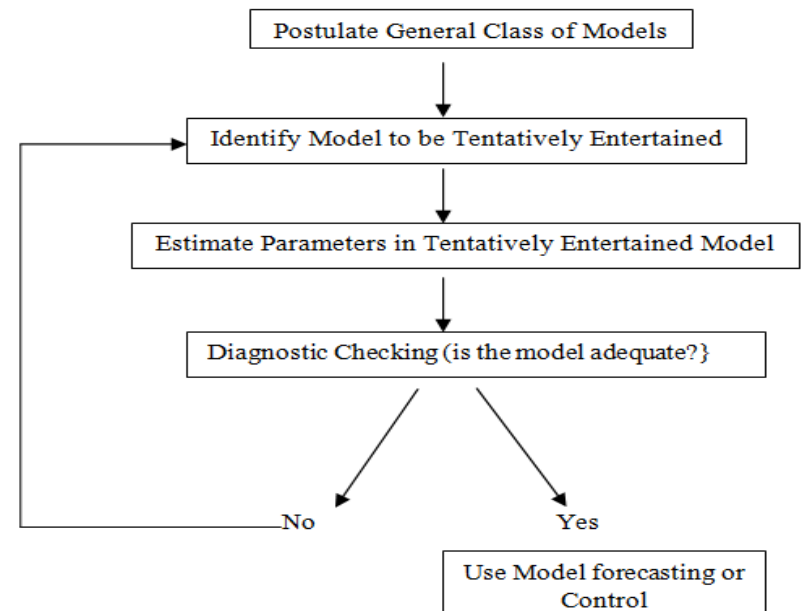

FIG.1 Stages in the iterative approach to model building

The data:

\section{Results}

The variable used in the analysis is the medical oxygen consumption from 2005 to the end of 2014 and its available monthly. The source of data is the Monthly demand of oxygen by Soba University Hospital In Khartoum.

Stationary Test:

Sample: 2005M01 2014M12

Table: 1

Included Observations: 120

\begin{tabular}{|c|c|c|c|c|c|c|}
\hline Autocorrel & Partial Co & tic & $\mathrm{AC}$ & PAC & Q-Stat & Prob \\
\hline . $* * * *$ & |**** & & 0.556 & 0.556 & 37.996 & 0.000 \\
\hline . $* * * *$ &.$* *$ & & 0.504 & 0.282 & 69.519 & 0.000 \\
\hline | $* * *$ & $.1^{*}$ & & 0.426 & 0.107 & 92.234 & 0.000 \\
\hline . $* * * *$ & ** & & 0.515 & 0.282 & 125.66 & 0.000 \\
\hline |*** & .1. & & 0.377 & -0.050 & 143.73 & 0.000 \\
\hline |*** & 1. & & 0.367 & 0.031 & 161.03 & 0.000 \\
\hline . $* *$ & .1. & & 0.347 & 0.066 & 176.64 & 0.000 \\
\hline . *** & 1. & & 0.340 & -0.003 & 191.73 & 0.000 \\
\hline .** & * & & 0.328 & 0.076 & 205.89 & 0.000 \\
\hline .** & * & & 0.341 & 0.077 & 221.35 & 0.000 \\
\hline *** & 1. & & 0.293 & -0.033 & 232.88 & 0.000 \\
\hline .** & 1. & & 0.257 & -0.025 & 241.85 & 0.000 \\
\hline |** & .1. & & 0.256 & 0.014 & 250.82 & 0.000 \\
\hline |** & .1. & & 0.279 & 0.045 & 261.53 & 0.000 \\
\hline . $* *$ & .1. & & 0.268 & 0.047 & 271.52 & 0.000 \\
\hline $.1^{*}$ & $* * \mid$. & & 0.119 & -0.215 & 273.50 & 0.000 \\
\hline
\end{tabular}


Modeling Medical Oxygen Demand Using Box-Jenkins Methodology Applied Study on Soba....

\begin{tabular}{|c|c|c|c|c|c|c|}
\hline .** & .* & 17 & 0.239 & 0.172 & 281.59 & 0.000 \\
\hline$f^{* * *}$ & .1 & 18 & 0.248 & 0.072 & 290.41 & 0.000 \\
\hline *** & .* & 19 & 0.299 & 0.080 & 303.36 & 0.000 \\
\hline * & *. & 20 & 0.129 & -0.130 & 305.79 & 0.000 \\
\hline.$^{*}$ & $*$ *. & 21 & 0.152 & -0.095 & 309.22 & 0.000 \\
\hline . $^{*}$ & $* 1$. & 22 & 0.103 & -0.066 & 310.80 & 0.000 \\
\hline . * $^{\circ}$ & $* 1$. & 23 & 0.085 & -0.095 & 311.88 & 0.000 \\
\hline .1 & .1. & 24 & 0.018 & -0.060 & 311.93 & 0.000 \\
\hline .1 & .1. & 25 & 0.013 & -0.034 & 311.96 & 0.000 \\
\hline. & .1. & 26 & -0.004 & 0.007 & 311.96 & 0.000 \\
\hline .1. & .1. & 27 & 0.011 & 0.014 & 311.97 & 0.000 \\
\hline .1. & .1. & 28 & 0.034 & 0.057 & 312.16 & 0.000 \\
\hline .1. & .1 & 29 & 0.061 & 0.061 & 312.77 & 0.000 \\
\hline .1. & .1 & 30 & 0.005 & -0.011 & 312.78 & 0.000 \\
\hline$*$. & $* 1$. & 31 & -0.093 & -0.198 & 314.21 & 0.000 \\
\hline .1. & .1 & 32 & -0.034 & -0.016 & 314.40 & 0.000 \\
\hline$*$. & $* 1$. & 33 & -0.112 & -0.129 & 316.53 & 0.000 \\
\hline$* 1$. &. & 34 & -0.125 & -0.026 & 319.17 & 0.000 \\
\hline ***. & .1. & 35 & -0.211 & -0.031 & 326.87 & 0.000 \\
\hline$*$. & .1. & 36 & -0.091 & 0.039 & 328.31 & 0.000 \\
\hline
\end{tabular}

Figure: 2

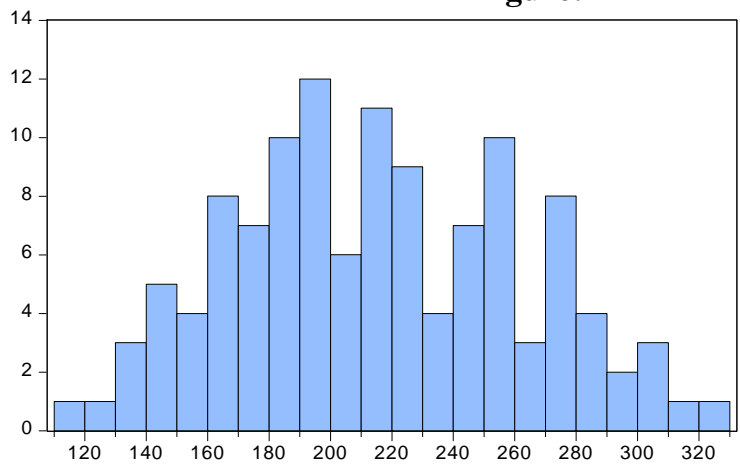

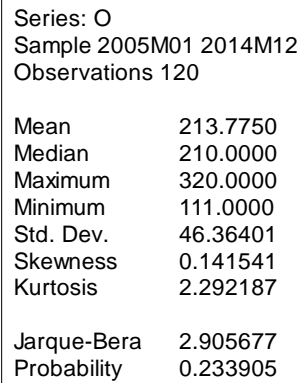

Table 1.\& Figure2. Show that the medical oxygen consumption rate from 2005 to 2014. Source: Monthly registration of oxygen demand of Soba University Hospital In Khartoum.

The first step in developing a Box-Jenkins model is to determine if the series is stationary. For this, we use the autocorrelation function (ACF) and Augmented Dickey-Fuller test (ADF).This section is devoted to the application of Augmented Dickey Fuller of unit root and correlogram tests in testing whether the medical oxygen consumption series is stationary. The correlogram test is one of the most powerful statistical tests used in testing whether the time-series data is stationary, the null hypothesis of the test is that all autocorrelations is equal to zero against the alternative hypothesis at one of the autocorrelations is not equal to zero. The acceptance of the null hypothesis all autocorrelations is equal to zero is an indication of stationarity series. While the Augmented Dickey Fuller test is testing the stationarity of the series under the null hypothesis that the series has a unit root against the alternative hypothesis the series does has a unit root, the acceptance of the null hypothesis is an indication of non-stationarity series.

Table:2 Null Hypothesis: O has a unit root

Exogenous: Constant

Lag Length: 3 (Automatic - based on SIC, maxlag=12)

\begin{tabular}{ccc}
\hline \hline Prob.* & t-Statistic & \\
\hline \hline 0.3739 & -1.810335 & Augmented Dickey-Fuller test statistic \\
\hline & -3.487550 & $1 \%$ level Test critical values: \\
& -2.886509 & $5 \%$ level \\
-2.580163 & $10 \%$ level \\
\hline \hline
\end{tabular}

*MacKinnon (1996) one-sided p-values. 
Augmented Dickey-Fuller Test Equation

Dependent Variable: $\mathrm{D}(\mathrm{O})$

Method: Least Squares

Sample (adjusted): 2005M05 2014M12

Included observations: 116 after adjustments

\begin{tabular}{ccccc}
\hline \hline Prob. & t-Statistic & Std. Error & Coefficient & Variable \\
\hline \hline 0.0729 & -1.810335 & 0.088909 & -0.160955 & $\mathrm{O}(-1)$ \\
0.0000 & -4.632861 & 0.108673 & -0.503466 & $\mathrm{D}(\mathrm{O}(-1))$ \\
0.0034 & -2.996282 & 0.107304 & -0.321513 & $\mathrm{D}(\mathrm{O}(-2))$ \\
0.0004 & -3.626825 & 0.089436 & -0.324369 & $\mathrm{D}(\mathrm{O}(-3))$ \\
0.0589 & 1.908583 & 19.17717 & 36.60121 & $\mathrm{C}$ \\
\hline \hline & & & $0.367095 \mathrm{R}-$ squared \\
1.215517 & Mean dependent var & 0.344288 Adjusted R-squared \\
42.66631 & S.D. dependent var & 34.54949 S.E. of regression \\
9.964810 & Akaike info criterion & 132497.1 Sum squared resid \\
10.08350 & Schwarz criterion & -572.9590 Log likelihood \\
10.01299 & Hannan-Quinn criter. & 16.09547 F-statistic \\
2.007821 & Durbin-Watson stat & 0.000000 Prob(F-statistic) \\
\hline \hline
\end{tabular}

Table2. show that the Augmented Dickey Fuller unit root test is employed for testing whether medical oxygen consumption series is stationary. Also in determining the order of differencing required in performing time series models. The Augmented Dickey-fuller of unit root test (ADF) with trend, intercept and lag difference of 1 result in above figure shows that the ADF value in absolute terms (1.810335) is less than the $1 \%, 5 \%$ and $10 \%$ critical values in absolute terms $(3.487550,2.886509$ and 2.580163$)$ respectively, this results conclude that medical oxygen consumption series has a unit root.

\section{The identification - the autocorrelation is computed on the first differences series}

Figure 3.

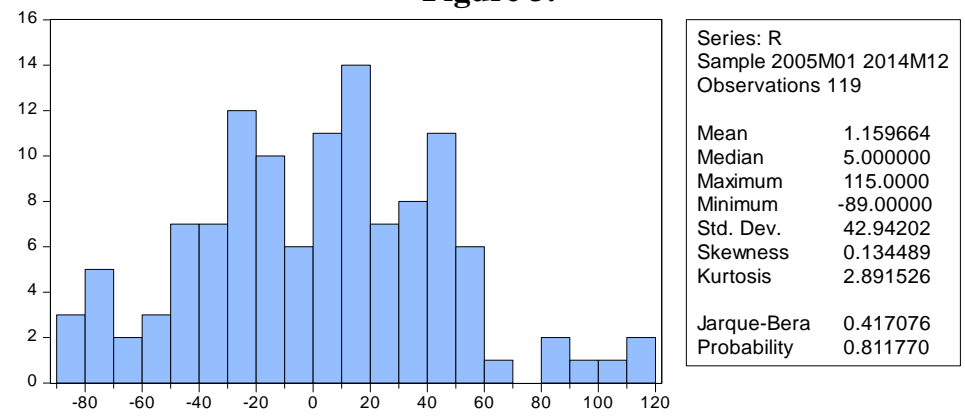

Table:3

Sample: 2005M01 2014M12

Included observations: 119

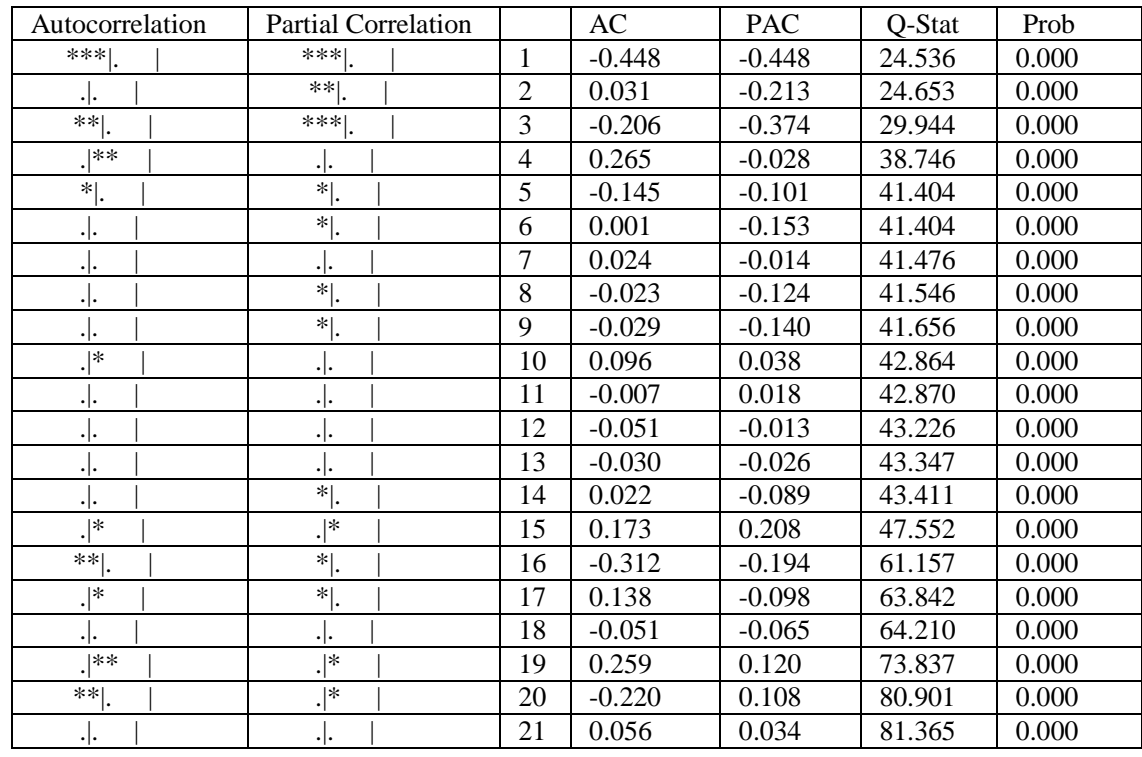


Modeling Medical Oxygen Demand Using Box-Jenkins Methodology Applied Study on Soba....

\begin{tabular}{|c|c|c|c|c|c|c|}
\hline .1 & .1. & 22 & -0.039 & 0.034 & 81.587 & 0.000 \\
\hline .1 &. & 23 & 0.021 & -0.021 & 81.653 & 0.000 \\
\hline .1. &. & 24 & -0.020 & -0.020 & 81.711 & 0.000 \\
\hline .1 & .1. & 25 & 0.012 & -0.048 & 81.732 & 0.000 \\
\hline .1. & .1. & 26 & -0.033 & -0.056 & 81.900 & 0.000 \\
\hline$\%$ & *1. & 27 & -0.035 & -0.106 & 82.087 & 0.000 \\
\hline .1 & $*$ *. & 28 & 0.016 & -0.121 & 82.128 & 0.000 \\
\hline.$^{*}$ & .1. & 29 & 0.110 & -0.034 & 84.056 & 0.000 \\
\hline .1. & . & 30 & 0.049 & 0.160 & 84.439 & 0.000 \\
\hline$* \mid$ & .1 & 31 & -0.193 & -0.011 & 90.532 & 0.000 \\
\hline.$^{*}$ & . * & 32 & 0.170 & 0.152 & 95.332 & 0.000 \\
\hline$*$. & .1 & 33 & -0.110 & 0.014 & 97.365 & 0.000 \\
\hline$I^{*}$ &. & 34 & 0.100 & -0.007 & 99.044 & 0.000 \\
\hline ***|. & . & 35 & -0.233 & -0.047 & 108.34 & 0.000 \\
\hline.$\left.\right|^{*}$ &. & 36 & 0.210 & -0.047 & 115.97 & 0.000 \\
\hline
\end{tabular}

Figure $3 \&$ Table 3. Show that the autocorrelation is computed on the first differences series

Table 4.

Null Hypothesis: R has a unit root Exogenous: Constant

Lag Length: 2 (Automatic - based on SIC, maxlag=12)

\begin{tabular}{|c|c|c|c|c|}
\hline Prob. ${ }^{*}$ & \multicolumn{4}{|l|}{ t-Statistic } \\
\hline 0.0000 & \multicolumn{4}{|c|}{-11.43476 Augmented Dickey-Fuller test statistic } \\
\hline & \multicolumn{2}{|l|}{$\begin{array}{l}-3.487550 \\
-2.886509 \\
-2.580163\end{array}$} & \multicolumn{2}{|c|}{$1 \%$ level Test critical values: } \\
\hline \multicolumn{5}{|c|}{$\begin{array}{l}\text { Augmented Dickey-Fuller Test Equation } \\
\text { Dependent Variable: } D(R) \\
\text { Method: Least Squares } \\
\text { Date: 06/27/16 Time: } 18: 02 \\
\text { Sample (adjusted): } 2005 \mathrm{M} 05 \text { 2014M12 } \\
\text { Included observations: } 116 \text { after adjustments }\end{array}$} \\
\hline Prob. & t-Statistic & Std. Error & Coefficient & Variable \\
\hline $\begin{array}{l}0.0000 \\
0.0000 \\
0.0000 \\
0.4659\end{array}$ & $\begin{array}{r}-11.43476 \\
4.936855 \\
4.319492 \\
0.731668\end{array}$ & $\begin{array}{l}0.210293 \\
0.158149 \\
0.086248 \\
3.245993\end{array}$ & $\begin{array}{r}-2.404647 \\
0.780761 \\
0.372548 \\
2.374990\end{array}$ & $\begin{array}{c}\mathrm{R}(-1) \\
\mathrm{D}(\mathrm{R}(-1)) \\
\mathrm{D}(\mathrm{R}(-2)) \\
\mathrm{C}\end{array}$ \\
\hline $\begin{array}{l}0.689655 \\
73.25541 \\
9.976666 \\
10.07162 \\
10.01521 \\
2.030951\end{array}$ & $\begin{array}{l}\text { Mean depend } \\
\text { S.D. depende } \\
\text { Akaike info cri } \\
\text { Schwarz criter } \\
\text { Hannan-Quinı } \\
\text { Durbin-Watso }\end{array}$ & $\begin{array}{l}\text { t var } \\
\text { var } \\
\text { rion } \\
\text { n } \\
\text { riter. } \\
\text { stat }\end{array}$ & $\begin{array}{c}0.778962 \mathrm{R} \\
0.773042 \mathrm{~A} \\
34.89897 \mathrm{~S} \\
136409.1 \mathrm{~S} \\
-574.6466 \mathrm{~L} \\
131.5671 \mathrm{~F} \\
0.000000 \mathrm{P}\end{array}$ & $\begin{array}{l}\text { R-squared } \\
\text { Adjusted R-squared } \\
\text { S.E. of regression } \\
\text { Sum squared resid } \\
\text { Log likelihood } \\
\text { F-statistic } \\
\text { Prob(F-statistic) }\end{array}$ \\
\hline
\end{tabular}

Table 4. Shows the ADF test were also applied to the first difference of medical oxygen consumption series from above figure the result illustrate that the absolute value of the ADF test (11.43476) is grater than the $1 \%, 5 \%$ and $10 \%$ critical values in absolute terms $(3.487550,2.886509$ and 2.580163$)$ respectively, this result conclude that the first difference of medical oxygen consumption rate series is stationary.

\section{Model identification and Coefficient Estimates:}

After the test of stationary, we conclude that the data is stationary at first difference. The repressor that would be chosen from the model is selected from various iteration for $\mathrm{AR}(\mathrm{p})$ and MA(q), the selection is based on observing the ACFs and PACFs. We used E-views for estimating the coefficients and testing the goodness of fit of the model. The search algorithm tried number of different coefficient values, after several iterations, and based on comparing Akaike Information Criteria (AIC), and Schwarz Information criteria (SIC), the best model to forecast medical oxygen demand is ARIMA $(0,1,1)$ since it contains the least AIC and SIC ratios. Table 5 shows the AIC and SIC value for various ARIMA (p,d,q) iterations: 
Table 5

\begin{tabular}{|l|l|l|}
\hline ARIMA (p,d,q). & AIC & SIC \\
\hline ARIMA (1,1,0) & 10.15862 & 10.205 \\
\hline ARIMA ( 0,1,1) & $\mathbf{9 . 9 6 8 4 4 9}$ & $\mathbf{1 0 . 0 1 5}^{\mathbf{*}}$ \\
\hline ARIMA (1,1,1) & 9.984488 & 10.054 \\
\hline ARIMA (1,1,2) & 9.986844 & 10.024 \\
\hline ARIMA (2,1,1) & 9.985561 & 10.079 \\
\hline ARIMA (2,1,2) & 9.999428 & 10.117 \\
\hline
\end{tabular}

Forecasting Accuracy: There are several methods of measuring accuracy and comparing one forecasting method to another, we have selected Root Mean Square Error (RMSE). Mean Absolute Error (MAE) and Mean Absolute Percentage Error (MAPE). The RMSE, MAE and MAPE are as follows :

\begin{tabular}{|l|l|}
\hline & ARIMA $(0,1,1)$ \\
\hline RMSE & 42.76187 \\
\hline MAE & 34.54954 \\
\hline MAPE & 97.84004 \\
\hline
\end{tabular}

The above table shows that the Root Mean Squared Error and Mean Absolute Error are less in ARIMA( $(0,1,1)$ as compared to other ARIMA models .

Forecast Result Analysis: Therefore, the estimation of ARIMA $(0,1,1)$ model is validated, the time series can be described by an $\operatorname{ARIMA}(0,1,1)$ process.

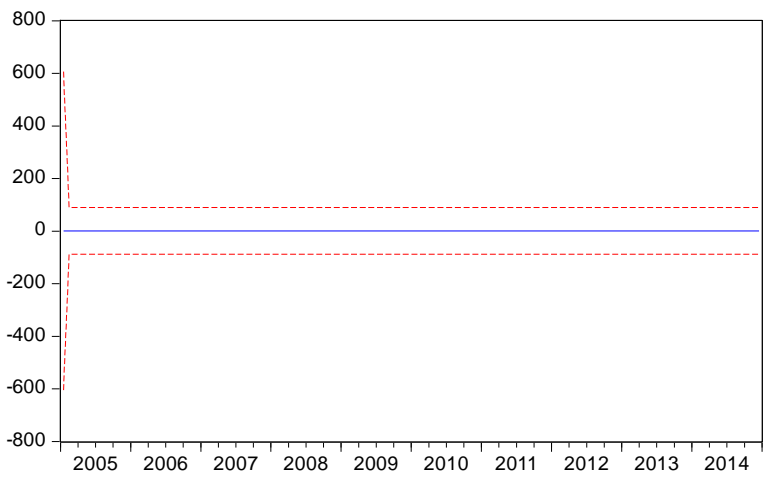

\begin{tabular}{|ll}
\hline \multicolumn{2}{l}{ Forecast: RF } \\
Actual: R \\
Forecast sample: 2005M01 2014M12 \\
Included observations: 119 \\
Root Mean Squared Error & 42.76187 \\
Mean Absolute Error & 34.54954 \\
Mean Abs. Percent Error & 97.84004 \\
Theil Inequality Coefficient & 0.978581 \\
\multicolumn{1}{l}{ Bias Proportion } & 0.000031 \\
Variance Proportion & NA \\
Covariance Proportion & NA \\
\hline
\end{tabular}

Forecasting model is: $\quad w_{t}=a_{t}-\theta_{1} a_{t-1}$

$$
\begin{aligned}
& M O D=0.920890+0.774676 a_{t-1} \\
& \text { t-Statistic } 1.229735 \quad-12.90649 \\
& \text { P-value } 0.2213 \quad 0.0000 \\
& \mathrm{DW}=1.876080, \mathrm{R} \text { Square }=0.339200, \mathrm{SSR}=143786.1
\end{aligned}
$$

\section{Conclusion}

In order to develop a univariate Time Series Model, we used medical oxygen consumption of Soba University Hospital in Khartoum state from January 2005 till December 2014.In this paper, we have developed systematic and iterative methodology of Box-Jenkins ARIMA forecasting for medical oxygen demand . A unit root test was applied to the long term monthly consumption of oxygen .This concludes that the oxygen demand series is non stationary. After the test of stationary, we conclude that the data is stationary at first difference, Eviews software is used for fitting the coefficient of the model, using graphs, statistics, ACFs and PACFs of residuals and after several iterations, the model selected is $\operatorname{ARIMA}(0,1,1)$. There are several ways of measuring forecasting accuracy; we have used Mean Absolute Error, Root Mean, Square Error and Mean Absolute Percentage Error. We may use this model for forecasting the medical oxygen demand for future.

\section{References}

[1]. Akaike, H. (1973) "Information theory and an extension of the maximum likelihood principle". In B.N. Petrov and B.F. Csaki, eds, Second International Symposium on Information Theory pp. 267-281, Akademiai Kiad 'o, Budapest.

[2]. Adriana AnaMaria ALEXANDRU.2008. "MODELLING UNEMPLOYMENT RATE USING BOX-JENKINS PROCEDURE".journal of applied quantitative methods.vol3.p [156-166]. 
[3]. American National Home Oxygen Patients Association (NHOPA) Reviewed and Revised 2013 (By: Dennis E. Doherty, MD, Physician Member of NHOPA Board of Directors ) Source URL :www.homeoxygen.com

[4]. Box, G. E. P. and Jenkins, G. M. (1976). Time Series Analysis Forecasting and Control, 2nd ed., Holden-Day, San Francisco.

[5]. Box, G and Cox, R. (1964) "An analysis of transformations," Journal of the Royal Statistical Society, Series B 26, pp.211-252

[6]. Box, G. and Jenkins, G. (1970) "Time series analysis: Forecasting and control ," San Francisco: Holden-Day

[7]. Box, G. and Pierce, D. (1970) "Distribution of Residual Autocorrelations in Autoregressive-Integrated Moving Average Time Series Models", Journal of the American Statistical Association, 65: pp.1509-1526.

[8]. Beverly D. Bradley, Stephen R. C. Howie, Timothy C. Y. Chan,Yu-Ling Cheng. 2014. Estimating Oxygen Needs for Childhood Pneumonia in Developing Country Health Systems. Plos One. 9(2).

[9]. Dickey D. and Fuller W.(1979), " Distribution of the estimators for Autoregressive Time Series With a unit Root ", Journal of the American Statistical Association,74: pp .427-431.

[10]. Dickey D. and Fuller W.(1981) 'The likelihood Ratio Statistics for Autoregressive Time Series With a unit Root", Econometric a ,n49: pp .1057-1072.

[11]. FULLER A.W. (1996) "Introduction to Statistical Time Series". JOHN WILEY \& SONS, INC, New York.

[12]. FederalMinistryofHealthofSudan1997.SourceURLhttp://www.sho.gov.sd/controller/knb_research_articles.php?lid=1\&id=2452\&sm _id=\&mid=109\&query=.

[13]. M. Massarrat Ali Khan.2013. Forecasting of Gold Prices (Box Jenkins Approach). International Journal of Emerging Technology and Advanced Engineering. ISSN 2250-2459, ISO 9001:2008 Certified Journal, Volume 3, Issue 3.P[662- 670].

[14]. SPYROS MAKRIDAKIS_AND MICHEÁ LE HIBON.1997. ARMA Models and the Box-Jenkins Methodology. Journal of Forecasting, Vol. 16, P[147-163]. 